\title{
Assessment of Knowledge and Practices of Standard Precaution against Blood Borne Pathogens among Doctors and Nurses at Adult Emergency Room in Addis Ababa, Ethiopia
}

\author{
Yohanis Asmr, ${ }^{1}$ Lemlem Beza, ${ }^{2}$ Hywot Engida, ${ }^{2}$ \\ Tariku Bekelcho, ${ }^{3}$ Netsanet Tsegaye, ${ }^{1}$ and Yibeltal Aschale $\mathbb{D i}^{4}$ \\ ${ }^{1}$ Department of Emergency Medicine and Critical Care Nursing, College of Medicine Health Science, \\ University of Gondar, Gondar, Ethiopia \\ ${ }^{2}$ Department of Emergency Medicine and Critical Care Nursing, College of Medicine and Health Science, \\ Addis Ababa University, Ethiopia \\ ${ }^{3}$ Department of Emergency Medicine and Critical Care Nursing, College of Medicine and Health Science, \\ Arba Minch University, Ethiopia \\ ${ }^{4}$ Department of Medical Parasitology, College of Health Sciences, Debre Markos University, Debre Markos, Ethiopia
}

Correspondence should be addressed to Yibeltal Aschale; yibeltal.aschale@yahoo.com

Received 23 January 2019; Revised 8 March 2019; Accepted 31 March 2019; Published 23 April 2019

Academic Editor: Seiji Morita

Copyright (C) 2019 Yohanis Asmr et al. This is an open access article distributed under the Creative Commons Attribution License, which permits unrestricted use, distribution, and reproduction in any medium, provided the original work is properly cited.

Background. Standard precautions are infection control techniques against pathogenic microorganisms that are present in human blood and can cause disease in humans. Objective. This study aims to assess knowledge and practice of standard precautions against blood borne pathogens among doctors and nurses in adult emergency room, Addis Ababa, Ethiopia. Methods. Institutional based cross sectional study was conducted from February to March 2018. A total of 128 study participants selected from four public hospitals were enrolled in this study. Data were collected using standardized pretested questionnaire and thencoded, entered, checked for completeness, and analyzed using SPSS version-23 statisticalsoftware. Chi-square test was used to measure the association between variables. $P$ values $<0.05$ were taken as statistically significant. Result. The mean knowledge score of standard precaution measures was 10.3 out of 14 knowledge items. Out of 32 doctors, $93.8 \%(n=30)$ have good knowledge and out of 91 nurses, $86.8 \%(\mathrm{n}=79)$ have good knowledge. The mean practice level of the study subjects was 8.5 out of 12 practice items. Majority (73.6\%) of nurses have good practice level than doctors (21.8\%). Knowledge level was significantly associated with the presence of infection control officer, infection control guideline, and washing hands before touching patients. Profession, training, and the presence of infection control guideline in emergency room were significantly associated with practice level of respondents $(\mathrm{P}<0.05)$. Conclusion. Both nurses and doctors have good knowledge of standard precaution measures. However, nurses have better practice level than doctors. Orientation during employment and continuous training programs should be provided for the newly employed health workers. In addition sustainable supply systems should be available in each hospital management.

\section{Background}

Standard precautions are a set of precautionary measures designed to prevent transmissions of blood born infectious diseases [1]. Blood borne pathogens such as HIV, HBV, and $\mathrm{HCV}$ are the most serious and contributed to be a major threat in the workplace [2]. In practical terms, standard precautions include the use of gloves, aprons, goggles, suitable care of contaminated instruments (needles and sharps), house keeping with appropriate cleaning policies and ensuring strict adherence to standard practices. This needs provision of protective materials, proper training of health 
care providers, and adherence to sterilization and disinfection protocols $[1,3]$.

Occupational exposure to blood borne pathogens from needle sticks and other sharps injuries is a serious problem but it is often preventable [4]. The world health organization (WHO) estimated that, of the 35 million health care workers worldwide, three million experiences percutaneous exposures to blood borne pathogens each year. Among these exposed health care professionals, two million were exposed to HBV, 0.9 million to HCV, and 170,000 to HIV [2]. The incidence of needle stick injury in Ethiopia is $17.5 \%$ annually which is attributed to risky habit and inappropriate standard precaution compliance [5].

Standard precaution against blood borne pathogens refers to infection control techniques to pathogenic microorganism that are present in human blood and can cause disease in humans $[3,6]$. Health care workers standard precaution against blood borne pathogens is essential components of any strategy to prevent infectious diseases [7]. Health care providers who are prone to infections with blood borne pathogens are nurses, laboratory technicians, surgeons, housekeepers, morgue technicians, and nonnursing attendants $[8,9]$. Nurses are more likely to be exposed to microorganisms during their daily practice due to their frequent close contact with patients [10]. Doctors are also exposed to blood borne pathogens during blood work, physical examination and might develop infection [11].

The differences in knowledge of standard precaution by health care workers might be influenced by their variable type of training $[12,13]$. Absence of an enabling environment in the health institution such as lack of constant running water or shortage of personal protective equipment can lead to poor practices with standard precaution $[14,15]$. Compliance with standard precaution practice requires appropriate attitude of health workers over long periods of time demanding motivation and technical knowledge of them $[1,4]$. In health institutions of developing countries like Ethiopia, hand washing practice even though not strict is among the components of infection prevention techniques $[6,15]$.

Standard precautions have been widely promoted in high-income countries to protect health care workers from occupational exposure to blood borne pathogens and the consequent risk of infection. Standard precautions are often practiced partially there by exposing the health care workers to unnecessary risk of infection with blood borne pathogens [2]. Even if Ethiopian Federal Minister of Health have clearly defined policies and procedures to implement standard precautions practice, less attention is given in facility level for the preventive strategies in reducing occupational injuries and infection. Assessing knowledge and practice of standard precautions against blood borne pathogens particularly in those health professionals working in emergency department is a life-saving procedure. There is no study conducted specifically on knowledge and practices of standard precaution against blood borne pathogens.

Therefore, this study is preliminarily intended to assess knowledge and practice of standard precautions against blood borne pathogens among doctors and nurses in the emergency room which is very important in differentiating the gap and implementing standard precautions against infectious pathogens. Findings from this study will help in planning and implementing appropriate interventions to improve compliance to standard precautions mainly related to blood borne pathogens among doctors and nurses.

\section{Materials and Methods}

2.1. Study Area. The study was conducted in Addis Ababa, Ethiopia, in four selected hospitals, Tikure Anbessa Specialized Hospital (TASH), Yekatit 12 Hospital Medical College (Y12 HMC), Menelik II Referral Hospital (Menelik II RH), and Zewditu Memorial Referral Hospital (Zewditu MRH) in adult emergency room. The TASH is one of the emergency centers in Addis Ababa which was established in 1973 during the regime of Emperor Haile Selassie. There is high patient flow where people get emergency medical and nursing care services. Zewditu MRH is also found in Central Addis Ababa. It is the leading hospital in the treatment of ART patients which currently treats over 6,000 patients each month and also gives general emergency health services. Menelik II RH and Yekatit $12 \mathrm{HMC}$ are also the oldest hospitals which are providing general emergency management services and other health related services.

2.2. Study Design and Period. Institutional based cross sectional quantitative study was conducted in four hospitals found in Addis Ababa to assess knowledge and practice of standard precautions against blood borne pathogens among doctors and nurses from February 2018 to March 2018.

2.3. Study Population Characteristics. The source population of this study was all physicians and nurses who are working in each adult emergency department of four selected hospitals. All physicians (seniors, residents, and general practitioners) and nurses (Diploma, BSc, and MSc) who are working in adult emergency department and willing to participate in the study were enrolled in this study. Physicians and nurses who were not present in their work place during the study period were excluded from the study.

2.4. Sampling Techniques. The study was conducted in Addis Ababa in the four public hospitals. These hospitals were selected purposively. To obtain study subjects from selected hospitals, stratified random sampling method was used. Stratification was into two strata (doctors and nurses). Then, the number of doctors and nurses who work in adult emergency management room were proportionally allocated in accordance with the total number of source population obtained from each emergency department. Finally, the respondents were selected by simple random sampling technique using lottery method.

2.5. Sample Size Determination. The sample size was determined using single population proportion formula: $[n=z 2 p$ $(1-p) / \mathrm{d} 2$ ] considering $95 \% \mathrm{CI}$ and $50 \%$ prevalence which is 384. Since the total population is less than 10,000 , the final corrected sample size was 128 using the population correction formula. 
TABLE 1: Sociodemographic characteristics of doctors and nurses in selected hospitals, February 19 to March 31;, 2018.

\begin{tabular}{|c|c|c|c|c|c|c|}
\hline \multirow{2}{*}{ Variables } & & \multicolumn{2}{|c|}{ Doctors $(n=32)$} & \multicolumn{2}{|c|}{ Nurse $(\mathrm{n}=91)$} & \multirow{2}{*}{ P-value } \\
\hline & & Number & Percent & Number & Percent & \\
\hline \multirow{5}{*}{ Age group (year) } & $22-27$ & 13 & 40.6 & 51 & 56 & 0.15 \\
\hline & $28-33$ & 16 & 50 & 30 & 33 & \\
\hline & $34-39$ & 2 & 6.3 & 5 & 5.5 & \\
\hline & $>40$ & 1 & 3.1 & 5 & 5.5 & \\
\hline & Total & 32 & 100 & 91 & 100 & \\
\hline \multirow{3}{*}{ Sex } & Male & 20 & 62.5 & 46 & 50.5 & 0.04 \\
\hline & Female & 12 & 37.5 & 45 & 49.5 & \\
\hline & Total & 32 & 100 & 91 & 100 & \\
\hline \multirow{4}{*}{ Marital status } & Divorced & 1 & 3.1 & 1 & 1.1 & 0.09 \\
\hline & Married & 11 & 34.4 & 40 & 44 & \\
\hline & Single & 20 & 62.5 & 50 & 54.9 & \\
\hline & Total & 32 & 100 & 91 & 100 & \\
\hline \multirow{4}{*}{ Work experience } & $<5$ & 28 & 87.5 & 63 & 69.2 & 0.34 \\
\hline & $5-10$ & 4 & 12.5 & 23 & 25.3 & \\
\hline & $>10$ & 0 & 0 & 5 & 5.5 & \\
\hline & Total & 32 & 100 & 91 & 100 & \\
\hline
\end{tabular}

2.6. Data Collection Tools and Techniques. Data were collected using self-administrated structured questionnaire which was adopted from previous study conducted in North Wollo Zone in 2006 on assessment of knowledge attitude and practice of health care workers on standard precautions. The questionnaire was developed in English version and translated to Amharic version then back to English to check consistency of questions. The questionnaire consists of three parts: sociodemographic information, knowledge assessment, and practices assessment. Knowledge was assessed using 14 questions which include multiple choice and yes or no questions. Practices were assessed in a similar way using 17 questions.

2.7. Data Entry and Analysis. Data were coded, entered, checked for completeness and analyzed using SPSS version23 statistical software. Respondents who scored greater than or equal to the mean score of knowledge questions were taken as good knowledge and responds who had greater than or equal to the mean score of practical questions were taken as good practices. Respondents who scored knowledge and practical questions below the mean were taken as poor knowledge and poor practices respectively. Descriptive statics were carried out to illustrate means, standard deviations, and frequency of the study variables. Chi-square test was used to measure the association between dependent and independent variables.

2.8. Data Quality Management. Data quality was managed during collection, coding, entry, and analysis steps. Pretest was conducted among $10 \%$ of the study population in Betel teaching hospital before the actual data collection to assess the reliability of data collection instruments and to avoid confusing questions. Then, corrective measures were taken on the data collection tools based on the pretest result.
The data collectors were first oriented on standardized data collection, particularly in the proper filling of questionnaire. One senior supervisor who monitored each level of data collection was assigned in each selected hospital to ensure weather the data collectors follow the proper and preplanned method of data collection or not. Data were then collected by the trained data collectors under close supervision of the supervisors to improve the quality. The supervisor and principal investigator has checked each collected data daily to make sure that whether all questions are properly filled or not.

\section{Result}

3.1. Sociodemographic Characteristics. From a total of 128 doctors and nurses, 123 fulfilled the inclusion criteria and participated in the study with the response rate of $96.1 \%$. Among these respondents, $66(53.7 \%)$ were males and 64 (52\%) were in the age range from 22 to 27 years (mean age 28 years). The majority (74.0\%) have less than 5 years of work experience (Table 1).

3.2. Training Status of the Study Participants. Among the study participants, $77(62.6 \%)$ have taken training on infection prevention. Of which, 67 (87.1\%) were nurses and 10 $(12.9 \%)$ were doctors. Less than half $(37.4 \%)$ of the respondents have not taken training on infection prevention at all.

3.3. Knowledge on Availability of Infection Prevention Officer and Guideline. About $64.2 \%(\mathrm{n}=79)$ of the respondents are aware of the presence of infection prevention officer and $35.8 \%(n=44)$ are not aware. About $62 \%(n=76)$ of the respondents are aware of the presence of infection prevention guideline, whereas $38 \%(n=47)$ are not aware of any guideline. 
TABLE 2: Knowledge of study participants on standard precautions against blood borne pathogens in selected hospitals, February to March 2018.

\begin{tabular}{|c|c|c|}
\hline Variables & Frequency & Percent \\
\hline \multicolumn{3}{|c|}{ Handwashing after touching patient intact skin } \\
\hline Always & 63 & 51.2 \\
\hline Often & 15 & 12.2 \\
\hline Sometimes & 39 & 31.7 \\
\hline Never & 6 & 4.9 \\
\hline \multicolumn{3}{|l|}{ Reason for reuse of syringe and needle } \\
\hline Shortage of supply & 23 & 18.7 \\
\hline Knowledge deficit & 67 & 54.5 \\
\hline Carelessness & 24 & 19.5 \\
\hline To reduce cost of treatment & 9 & 7.3 \\
\hline \multicolumn{3}{|c|}{ Had blood or body fluid splash to eye, mouth, or nose } \\
\hline Yes & 45 & 36.6 \\
\hline No & 74 & 60.2 \\
\hline Do not remember & 4 & 3.3 \\
\hline \multicolumn{3}{|c|}{ Measures taken after exposure to blood and body fluids } \\
\hline Wash with soap and water & 105 & 85.4 \\
\hline Wash with alcohol, iodine, chlorine & 42 & 34.1 \\
\hline Visiting VCT & 80 & 65.0 \\
\hline Seek PEP & 74 & 60.2 \\
\hline Report to head person & 61 & 49.6 \\
\hline Others $*$ & 25 & 20.3 \\
\hline \multicolumn{3}{|l|}{ Source of infection } \\
\hline Health personnel & 87 & 70.7 \\
\hline Contaminated medical equipment & 111 & 90.2 \\
\hline Contaminated air & 93 & 75.6 \\
\hline Other patients & 62 & 50.4 \\
\hline Others $* *$ & 24 & 19.5 \\
\hline
\end{tabular}

N.B: Others $*=$ consulting physicians; others $* *=$ insect and small animals.

3.4. Knowledge on Standard Precaution against Blood Borne Pathogens. About $98.4 \% \quad(\mathrm{n}=121)$ of study participants reported that needle was one type of waste discarded in safety box. Majority (85.4\%) of study participants reported that they wash their hand with soap and water. Majority (51.2\%) of the study participants have reported that they wash their hands always after touching the patient. About $36.6 \%(n=45)$ of study participants reported a history of splashing and $60.2 \%(n=74)$ have no history of splashing (Table 2).

3.5. Mean Knowledge Score of the Study Participants. The mean knowledge score of all participants was 10.3 out of 14 knowledge items. About $89 \%$ of study participants have good knowledge (Figure 1).

\subsection{Practice Level of Participants on Standard Precaution} against Blood Borne Pathogens. Majority (28.5\%) of study participants do not wash their hands due to inaccessibility of hand washing materials. About $65 \%(n=80)$ of study participants have used personal protective equipment before touching the patients. The majority (95.1\%) of the study participants apply "use and throw" method after using of

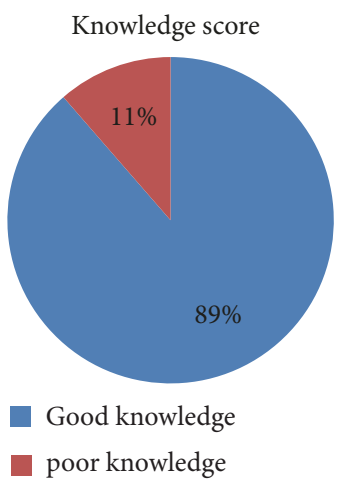

FIGURE 1: Knowledge score of study participants in selected hospitals.

materials like nasal cannula, prong, and face mask. About $79(64.2 \%)$ have reported that they have decontaminated laryngoscope after using it for intubation (Table 3).

3.7. Practice Score of Study Participants. The mean practice score of study participants was 8.56 out of 12 practices 
TABLE 3: Practice level of study participants on standard precaution against blood borne pathogens among study participants in selected hospitals, February to March 2018.

\begin{tabular}{|c|c|c|}
\hline Variables & Frequency & Percent \\
\hline \multicolumn{3}{|l|}{ Reasons for not washing hands } \\
\hline Inaccessibility of hand washing materials & 35 & 28.5 \\
\hline Not always necessary & 24 & 19.5 \\
\hline Absence of hand washing materials & 18 & 14.6 \\
\hline Emergency condition & 30 & 24.4 \\
\hline I use glove & 16 & 13 \\
\hline \multicolumn{3}{|l|}{ Wearing PPE before touching the patient } \\
\hline Yes & 80 & 65 \\
\hline No & 43 & 35 \\
\hline \multicolumn{3}{|l|}{ Device used as PPE } \\
\hline Apron & 37 & 30.1 \\
\hline Mask & 59 & 47.9 \\
\hline Utility glove & 71 & 57.7 \\
\hline Gown & 61 & 49.6 \\
\hline Eye protector glove & 29 & 23.6 \\
\hline Boots shoes & 42 & 31.1 \\
\hline \multicolumn{3}{|c|}{ How many times you sustained needle stick injury } \\
\hline 1 times/year & 27 & 69.2 \\
\hline 2 times/year & 9 & 23.1 \\
\hline$>3$ times/year & 3 & 7.7 \\
\hline \multicolumn{3}{|l|}{ Reuse of medical equipment's } \\
\hline Yes & 6 & 4.9 \\
\hline No & 117 & 95.1 \\
\hline \multicolumn{3}{|l|}{ Giving or decontaminate laryngoscope after use } \\
\hline Yes & 79 & 64.2 \\
\hline No & 44 & 35.8 \\
\hline
\end{tabular}

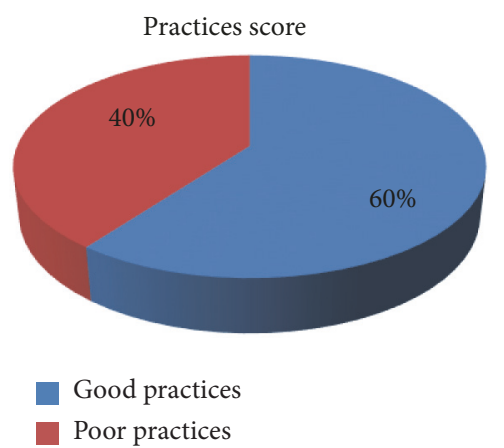

Figure 2: Practices score of the study participants in selected hospitals.

items. About $60 \%$ of study participants have good practice (Figure 2).

3.8. Factors Associated with Knowledge and Practice Level. There was significant associations between knowledge score of study participants and presence of infection control officers, infection prevention guidelines, and hand washing before touching patients $(\mathrm{P}<0.05)$ (Table 4$)$.
Statistically significant association was observed between practice score and professional categories, training, presence of infection control guideline, wearing personal protective equipment before touching patients and washing hands before touching the patients $(\mathrm{P}<0.05)$ (Table 5$)$.

\section{Discussion}

The finding of this study showed that the mean knowledge score of all participants was 10.3 out of 14 knowledge items and the mean score of practice was 8.56 out of 12 practice items. The overall knowledge score for both categories were $88.6 \%$ and the remaining (11.4\%) of study participants had poor knowledge score. About $94.5 \%$ of doctors had good knowledge whereas $87 \%$ of nurses had good knowledge score. This is comparable with a study conducted in South East Nigeria in which about $97.0 \%$ of doctors had good knowledge score and $92.0 \%$ nurses had good knowledge score [8]. This similarity might be due to the fact that standard precautions have been incorporated in the nursing and medical student curriculum.

The overall practice score for both categories was $60.2 \%$ good practices and $39.8 \%$ poor practices. In this finding, nurses had good standard precautions practice against blood borne pathogens which accounted for $74 \%$ as compared to 
TABLE 4: Factors associated with knowledge level of the study subject in selected hospitals from February to March 2018.

\begin{tabular}{|c|c|c|c|c|c|c|}
\hline \multirow{3}{*}{ Variables } & \multirow{3}{*}{ Response } & \multicolumn{4}{|c|}{ Knowledge level } & \multirow{3}{*}{$P$ value } \\
\hline & & \multicolumn{2}{|c|}{ Poor } & \multicolumn{2}{|c|}{ Good } & \\
\hline & & $\mathrm{N}$ & $\%$ & $\mathrm{~N}$ & $\%$ & \\
\hline \multirow{2}{*}{ Training } & No & 8 & 17.4 & 38 & 82.6 & \multirow{2}{*}{0.105} \\
\hline & Yes & 6 & 7.8 & 71 & 92.2 & \\
\hline \multirow{2}{*}{ Profession } & Doctor & 2 & 6.2 & 30 & 93.8 & \multirow{2}{*}{0.862} \\
\hline & Nurse & 12 & 13.2 & 79 & 86.8 & \\
\hline \multirow{2}{*}{ Infection control officer } & No & 9 & 20.5 & 35 & 79.5 & \multirow{2}{*}{$0.018 *$} \\
\hline & Yes & 5 & 6.3 & 74 & 93.7 & \\
\hline \multirow{2}{*}{$\begin{array}{l}\text { Infection control guideline } \\
\text { in emergency room }\end{array}$} & No & 9 & 19.1 & 38 & 80.9 & \multirow{2}{*}{$0.033 *$} \\
\hline & Yes & 5 & 6.6 & 71 & 93.4 & \\
\hline \multirow{2}{*}{ Wearing gloves during invasive procedure } & No & 0 & 0 & 2 & 100 & \multirow{2}{*}{0.609} \\
\hline & Yes & 14 & 16.6 & 107 & 88.4 & \\
\hline \multirow{2}{*}{$\begin{array}{l}\text { Discarded, used material as per standard } \\
\text { precaution guideline }\end{array}$} & No & 2 & 5.3 & 36 & 94.7 & \multirow{2}{*}{0.153} \\
\hline & Yes & 12 & 14.1 & 73 & 85.9 & \\
\hline \multirow{2}{*}{ Reused needle or syringe } & No & 8 & 9 & 81 & 91 & \multirow{2}{*}{0.176} \\
\hline & Yes & 6 & 17.6 & 28 & 82.4 & \\
\hline \multirow{2}{*}{ Wash hands before touching the patients } & No & 11 & 17.2 & 53 & 82.8 & \multirow{2}{*}{$0.035 *$} \\
\hline & Yes & 3 & 5.1 & 56 & 94.9 & \\
\hline \multirow{2}{*}{$\begin{array}{l}\text { Wearing personal protective equipment's } \\
\text { before touching the patients }\end{array}$} & No & 7 & 16.3 & 36 & 83.7 & \multirow{2}{*}{0.21} \\
\hline & Yes & 7 & 8.8 & 73 & 91.3 & \\
\hline \multirow{2}{*}{ Have you ever had NSI } & No & 8 & 9.5 & 76 & 90.5 & \multirow{2}{*}{0.34} \\
\hline & Yes & 6 & 15.4 & 33 & 84.6 & \\
\hline
\end{tabular}

TABLE 5: Factors associated with practice level of the study participants in selected hospitals from February to March 2018.

\begin{tabular}{|c|c|c|c|c|c|c|}
\hline \multirow{3}{*}{ Variables } & \multirow{3}{*}{ Response } & \multicolumn{4}{|c|}{ Practice level } & \multirow{3}{*}{$P$ value } \\
\hline & & \multicolumn{2}{|c|}{ Poor } & \multicolumn{2}{|c|}{ Good } & \\
\hline & & $\mathrm{N}$ & $\%$ & $\mathrm{~N}$ & $\%$ & \\
\hline \multirow{2}{*}{ Training } & No & 36 & 78.3 & 10 & 21.7 & \multirow{2}{*}{$<0.05 *$} \\
\hline & Yes & 26 & 33.8 & 44 & 55.7 & \\
\hline \multirow{2}{*}{ Profession } & Doctor & 25 & 78.1 & 7 & 21.9 & \multirow{2}{*}{$<0.05 *$} \\
\hline & Nurse & 24 & 26.4 & 67 & 73.6 & \\
\hline \multirow{2}{*}{ Infection control officer } & No & 27 & 61.4 & 17 & 38.6 & \multirow{2}{*}{0.07} \\
\hline & Yes & 35 & 44.3 & 44 & 55.7 & \\
\hline \multirow{2}{*}{$\begin{array}{l}\text { Infection control guideline } \\
\text { in emergency room }\end{array}$} & No & 32 & 68.1 & 15 & 31.9 & \multirow{2}{*}{$0.002 *$} \\
\hline & Yes & 30 & 39.5 & 46 & 60.5 & \\
\hline \multirow{2}{*}{ Wearing gloves during invasive procedure } & No & 1 & 50 & 1 & 50 & \multirow{2}{*}{0.991} \\
\hline & Yes & 61 & 50.4 & 60 & 49.6 & \\
\hline \multirow{2}{*}{$\begin{array}{l}\text { Discarded used material as per standard } \\
\text { precaution guideline }\end{array}$} & No & 27 & 71.1 & 11 & 28.9 & \multirow{2}{*}{$0.002 *$} \\
\hline & Yes & 35 & 41.2 & 50 & 58.8 & \\
\hline \multirow{2}{*}{ Reused needle or syringe } & No & 35 & 39.3 & 54 & 60.7 & \multirow{2}{*}{$<0.05 *$} \\
\hline & Yes & 27 & 79.4 & 7 & 20.6 & \\
\hline \multirow{2}{*}{ Wash hands before touching the patients } & No & 42 & 65.6 & 22 & 34.4 & \multirow{2}{*}{$<0.05 *$} \\
\hline & Yes & 20 & 33.9 & 39 & 66.1 & \\
\hline \multirow{2}{*}{$\begin{array}{l}\text { Wearing personal protective equipment's } \\
\text { before touching the patients }\end{array}$} & No & 36 & 83.7 & 7 & 16.3 & \multirow{2}{*}{$<0.05 *$} \\
\hline & Yes & 26 & 32.5 & 54 & 67.5 & \\
\hline \multirow{2}{*}{ Have you ever had NSI } & No & 36 & 42.9 & 48 & 57.1 & \multirow{2}{*}{$<0.05 *$} \\
\hline & Yes & 26 & 66.7 & 13 & 33.3 & \\
\hline
\end{tabular}


doctors (21.8\%). This result is slightly higher than a study conducted in Southeast Nigeria among nurses and doctors, which has $75 \%$ good practices for nurses and only $15 \%$ for doctors [8]. This difference might be due to the difference in sample size and sampling methods.

In the recent study conducted in India of tertiary care hospitals on the knowledge, attitude and practice of standard precautions among medical and nursing students, nursing students had better knowledge compared with medical students which was $85.6 \%$ in nursing students and $75.6 \%$ in medical students. This might be responsible for the generally better compliance to standard precautions practice observed among nurses compared to other health practitioners [16].

In the present study $62.6 \%$ of the study participants had training on infection prevention which is directly related to infection prevention. Of which, $87 \%$ were nurses and the remaining $13 \%$ were doctors. This is slightly higher than a study conducted in TASH which is $49.2 \%$ [6] and in North Wollo Zone, Amhara region, by which only $45.8 \%$ of the respondents had prior training [17]. This difference might be due to lack of national guideline and learning materials on infection prevention in local language for health care workers, clients and communities and also could be due to absence of continuous support and supervision to improve the standard precaution.

According to this study there was no significant knowledge difference between male $(89.0 \%$ had good knowledge score) and female (88.0\% had good knowledge score) on standard precautions against blood borne pathogens. This is different from a study conducted in Jamaica which was highest among women compared with men, and among nurses (90.0\%), compared with medical doctors (88.0\%) [12].

In this study only $43.1 \%$ of the respondents have used personal protective equipment after sustaining needle stick or sharp injuries which is higher than the study conducted in TASH among emergency medicine professionals in which $24.6 \%$ of respondents used personal protective equipment after sustaining needle stick or sharp injuries [6]. This might be due to the difference in sample size and sampling methods.

According to this study $98.4 \%$ of the respondents have worn gloves during invasive procedures. However, a study conducted in Ghana, Accra Hospital, showed that $88 \%$ of respondents indicated that they have worn gloves routinely when performing invasive procedures on patients. This study demonstrated better practice in use of gloves in emergency rooms than the practice of Ghana Accra hospital health professionals [3]. This could be fear of the infectiousness of diseases like HIV and HBV due to their higher prevalence in Ethiopia.

Even though gloves, gowns, aprons, masks, and goggles are advised by the world health organization to help protect health care workers and clients from blood borne infections including HIV, in this study only $88.8 \%$ respondents worn utility gloves, $76.8 \%$ worn mask for invasive procedures, and $36.3 \%$ put on goggles. But study done in perceptions and practice of standard blood and body fluid precautions by registered nurses at a major Sydney teaching hospital showed that $84 \%$ of the respondents wear gloves face masks for invasive procedures. The least practiced is wearing of protective eye shields (24\%)[18]. This showed significant difference because of inaccessibility and absence of personal protective device particularly goggles and faces masks in emergency room.

In this study $36.6 \%$ of study participants have experienced blood born body fluid splash to mucus membrane. This is comparable with a study conducted in SNNPR in which $32.4 \%$ experienced blood born body fluid splash on the mucus membrane [19]. The results of the present findings were obtained in a hospital with a high patient flow and intensive health care services, whereas the previous study included health care workers working in health centers, which provide less intensive health care than hospitals [2].

Based on this study $61.5 \%$ of nurses have washed their hands always after touching patient intact skin. This finding is different from a study conducted in Thailand in which $75 \%$ of doctors and $47 \%$ of nurses have washed their hands after caring for patients, and $16 \%$ of doctors and $50 \%$ of nurses rubbed their hands with alcohol after washing them with an antiseptic [20]. Low level of hand washing practice among doctors in this study might be attributed to the absence of information during introductory on job training courses and orientation. In this study significantly higher number of trained study participants had good compliance of hand washing practices than those who had no training on infection prevention $(\mathrm{P}<0.05)$.

\section{Conclusion and Recommendation}

The study has demonstrated good knowledge of standard precaution against blood borne pathogens in both doctors and nurses. Nurses exhibited a significantly higher compliance to standard precaution practices compared to doctors. Training staffs on standard precautions, principles, and practice needs to be implemented to provide the necessary knowledge on compliance to standard precaution practices. In addition, strict supervision, operational guideline and on-job training courses and orientation need to be implemented regularly.

\section{Abbreviations \\ HIV: Human Immunodeficiency Virus \\ HBV: Hepatitis B Virus \\ HCV: Hepatitis C Virus.}

\section{Data Availability}

The data used to support the findings of this study are available from the corresponding author upon reasonable request.

\section{Ethical Approval}

Ethical clearance was obtained from School of Graduate Study, Addis Ababa University. Formal letter of cooperation was written from the Department of Emergency Medicine to TASH Emergency Nursing Service Directorate, Zewditu $\mathrm{MRH}$, Yekatit $12 \mathrm{MCH}$, and to Addis Ababa Health Bureau Ethical Review Committee. 


\section{Consent}

Informed written consent was obtained from the respondents and response of participants was kept confidential. Participants were informed that they can refrain from the study whenever they feel to do so. Only research team members were allowed to access the questioners. The responses given by the participants were not used for performance appraisal or as a component of work efficiency audit.

\section{Conflicts of Interest}

The authors declare that they have no conflicts of interest.

\section{Authors' Contributions}

Yohanis Asmr conceived the study and was involved in data collection and analysis. Lemlem Beza and Hywot Engida were involved in data collection and analysis. Yohanis Asmr wrote the first draft of the manuscript. Lemlem Beza, Hywot Engida, Netsanet Tsegaye, Tariku Bekelcho, and Yohanis Asmr critically reviewed the manuscript. All authors reviewed and approved the final version of the manuscript.

\section{Acknowledgments}

We would like to thank Addis Ababa University for funding this research. We are grateful to data collectors and study participants.

\section{References}

[1] M. Z. A. Hamid, N. A. Aziz, A. R. Anita, and O. Norlijah, "Knowledge of blood-borne infectious diseases and the practice of universal precautions amongst health-care workers in a tertiary hospital in Malaysia," Southeast Asian Journal of Tropical Medicine and Public Health, vol. 41, no. 5, pp. 1192-1199, 2010.

[2] M. A. Yenesew and G. A. Fekadu, "Occupational exposure to blood and body fluids among health care professionals in Bahir Dar Town, Northwest Ethiopia," Safety and Health at Work, vol. 5, no. 1, pp. 17-22, 2014.

[3] A. Hesse, N. Adu-Aryee, K. Entsua-Mensah, and L. Wu, "Knowledge, attitude and practice on universal basic precautions by medical personnel in a teaching hospital," Ghana Medical Journal, vol. 40, no. 2, article no. 61, 2006.

[4] M. Kermode, "Unsafe injections in low-income country health settings: need for injection safety promotion to prevent the spread of blood-borne viruses," Health Promotion International, vol. 19, no. 1, pp. 95-103, 2004.

[5] A. A. Reda, S. Fisseha, B. Mengistie, and J.-M. Vandeweerd, "Standard precautions: occupational exposure and behavior of health care workers in Ethiopia," PLOS ONE, vol. 5, no. 12, Article ID e14420, 2010.

[6] A. Alemayehu, Assessment of the Knowledge, Attitude and Practice on Universal Precaution among Emergency Medicine Professionals in Emergency Room Tikure Anbessa Specialized Hospital, AAU, Ethiopia, GC: Addis Ababa University, 2013.

[7] M. Kale, M. Gholap, and M. Shinde, "Knowledge and practices of universal precautions among basic BSc nursing students,"
International Journal of Science and Research, vol. 3, no. 6, pp. 1862-1870, 2014.

[8] E. D. Adinma, C. Ezeama, J. I. B. Adinma, and M. C. Asuzu, "Knowledge and practice of universal precautions against blood borne pathogens amongst house officers and nurses in tertiary health institutions in Southeast Nigeria," Nigerian Journal of Clinical Practice, vol. 12, no. 4, pp. 398-402, 2009.

[9] P. A. Murphy, "Prevention of HIV transmission in health care settings," Journal of Nurse-Midwifery, vol. 33, no. 1, pp. 41-42, 1988.

[10] H. G. Eskander, W. Y. Morsy, and H. A. Elfeky, "Intensive care nurses knowledge \& practices regarding infection control standard precautions at a selected egyptian cancer hospital," Prevention, vol. 4, no. 19, 2013.

[11] E. I. G. La-Rotta, C. S. Garcia, F. Barbosa, A. F. D. Santos, G. M. M. Vieira, and M. Carneiro, "Evaluation of the level of knowledge and compliance with standart precautions and the safety standard (NR-32) amongst physicians from a public university hospital, Brazil," Revista Brasileira de Epidemiologia, vol. 16, no. 3, pp. 786-797, 2013.

[12] K. Vaz, D. McGrowder, R. Alexander-Lindo, L. Gordon, P. Brown, and R. Irving, "Knowledge, awareness and compliance with universal precautions among health care workers at the University Hospital of the West Indies, Jamaica," The International Journal of Occupational and Environmental Medicine, vol. 1, no. 4, pp. 171-181, 2010.

[13] R. Chan, A. Molassiotis, C. Eunice et al., "Nurses' knowledge of and compliance with universal precautions in an acute care hospital," International Journal of Nursing Studies, vol. 39, no. 2, pp. 157-163, 2002.

[14] W. E. Sadoh, A. O. Fawole, A. E. Sadoh, A. O. Oladimeji, and O. S. Sotiloye, "Practice of universal precautions among healthcare workers," Journal of the National Medical Association, vol. 98, no. 5, pp. 722-724, 2006.

[15] T. Facile, "Investigating the compliance with universal precautions among health care providers," Ethiopian Journal of Health Development, vol. 25, no. 1, Article ID 2706807, 2009.

[16] B. Paul, A. Pawar, D. Kumar, and P. K. Sujesh, "A study on knowledge, attitude and practice of universal precautions among medical and nursing students," Scholars Journal of Applied Medical Sciences, vol. 2, no. 5E, pp. 1821-1823, 2014.

[17] M. Betre, Assessment of the Knowledge, Attitude and Practice of Health Care Workers on Universal Precaution, Addis Ababa University, 2007.

[18] V. M. Knight and N. J. Bodsworth, "Perceptions and practice of universal blood and body fluid precautions by registered nurses at a major Sydney teaching hospital," Journal of Advanced Nursing, vol. 27, no. 4, pp. 746-751, 1998.

[19] Y. Wolde-Gebriel, Assessment of the safety of injections and related medical practices in health institutions at Sidama Zone, SNNPRS. [MPH thesis], 2004.

[20] S. Danchaivijitr, Y. Tantiwatanapaiboon, S. Chokloikaew, T. Tangtrakool, L. Suttisanon, and L. Chitreechuer, "Universal precautions: knowledge, compliance and attitudes of doctors and nurses in Thailand." Journal of the Medical Association of Thailand, vol. 78, pp. S112-117, 1995. 


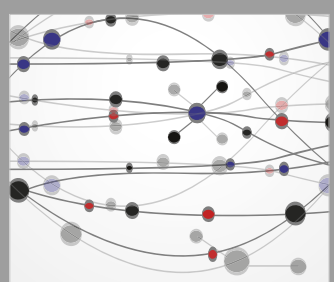

The Scientific World Journal
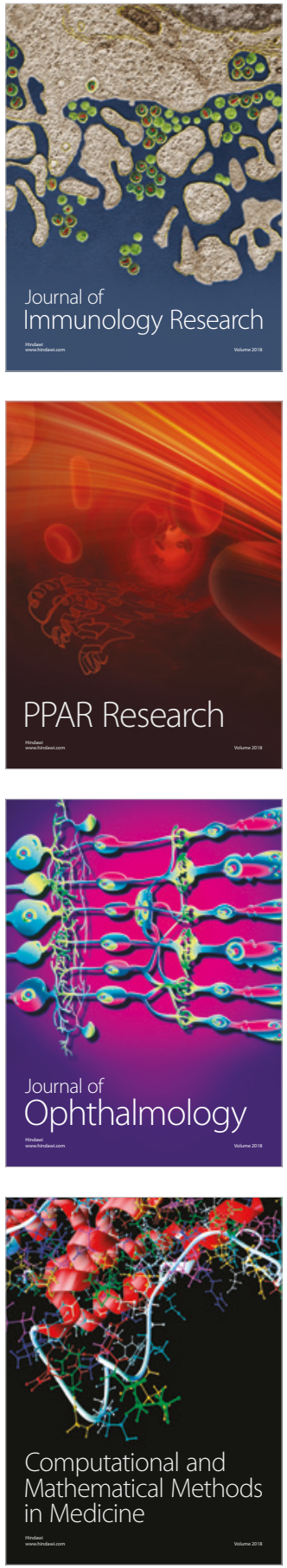

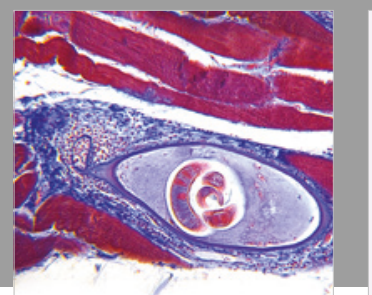

Gastroenterology Research and Practice

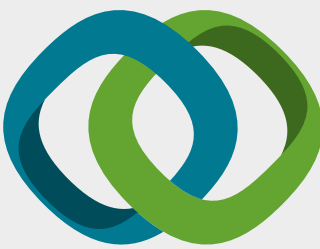

\section{Hindawi}

Submit your manuscripts at

www.hindawi.com
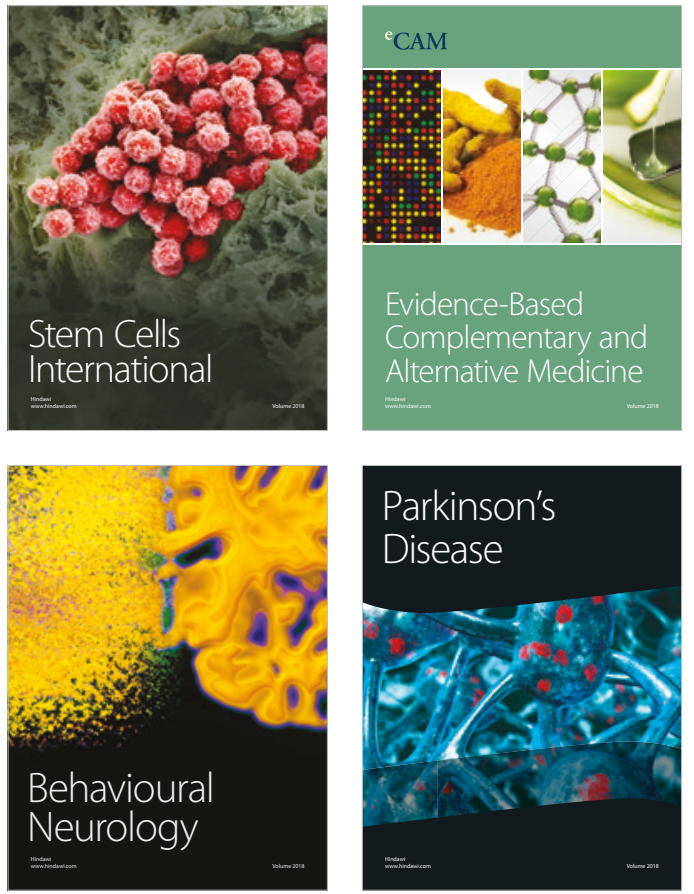

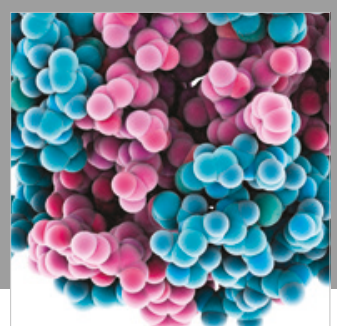

ournal of

Diabetes Research

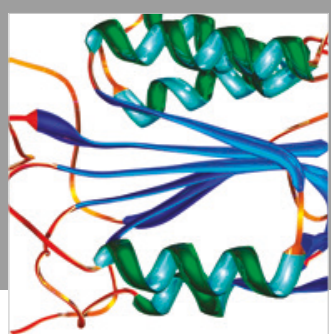

Disease Markers
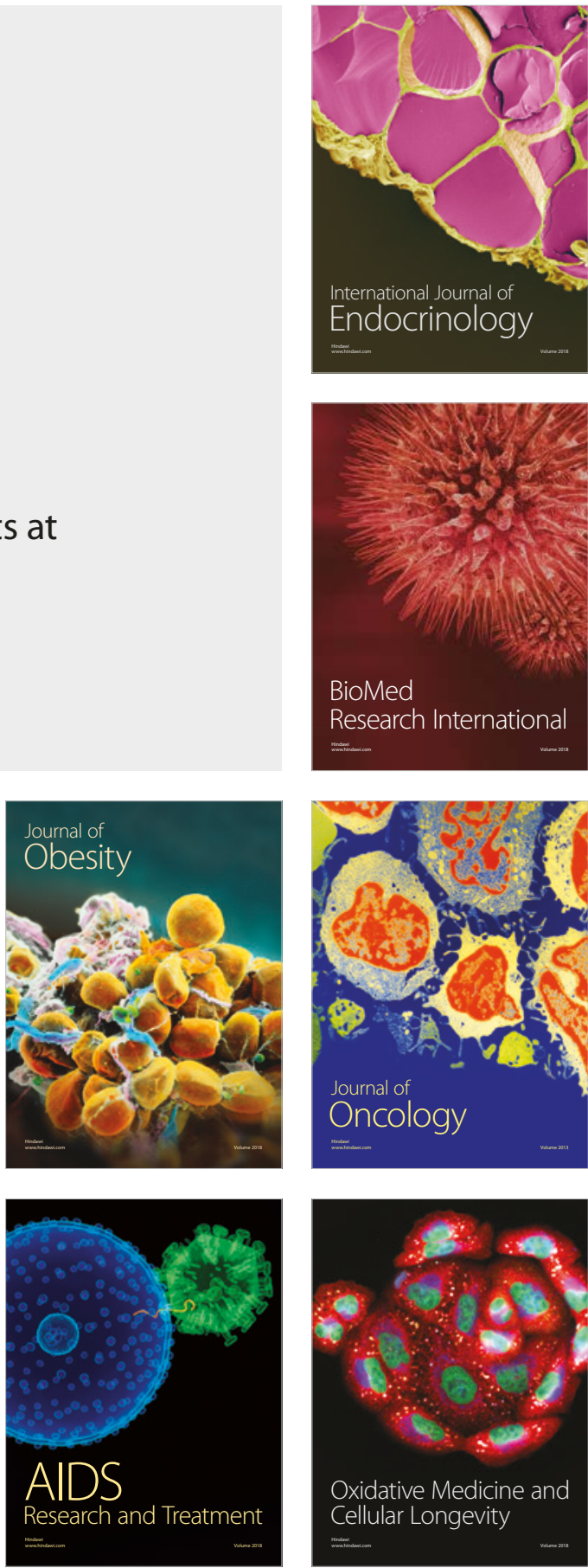